\title{
In vitro activity of ten essential oils against Sarcoptes scabiei
}

Fang Fang ${ }^{1,2}$, Kerdalidec Candy ${ }^{3}$, Elise Melloul ${ }^{2}$, Charlotte Bernigaud ${ }^{2,4}$, Ling Chai ${ }^{5}$, Céline Darmon², Rémy Durand ${ }^{3}$, Françoise Botterel ${ }^{2}$, Olivier Chosidow ${ }^{4}$, Arezki Izri ${ }^{3}$, Weiyi Huang ${ }^{1}$ and Jacques Guillot ${ }^{2^{*}}$

\begin{abstract}
Background: The development of alternative approaches in ectoparasite management is currently required. Essential oils have been demonstrated to exhibit fumigant and topical toxicity to a number of arthropods. The aim of the present study was to assess the potential efficacy of ten essential oils against Sarcoptes scabiei.

Methods: The major chemical components of the oils were identified by GC-MS analysis. Contact and fumigation bioassays were performed on Sarcoptes mites collected from experimentally infected pigs. For contact bioassays, essential oils were diluted with paraffin to get concentrations at 10, 5, and even 1\% for the most efficient ones. The mites were inspected under a stereomicroscope 10, 20, 30, 40, 50, 60, 90, 120, 150, and 180min after contact. For fumigation bioassay, a filter paper was treated with $100 \mu \mathrm{L}$ of the pure essential oil. The mites were inspected under a stereomicroscope for the first $5 \mathrm{~min}$, and then every $5 \mathrm{~min}$ until $1 \mathrm{~h}$.
\end{abstract}

Results: Using contact bioassays, 1\% clove and palmarosa oil killed all the mites within 20 and 50min, respectively. The oils efficacy order was: clove $>$ palmarosa $>$ geranium $>$ tea tree $>$ lavender $>$ manuka $>$ bitter orange $>$ eucalyptus $>$ Japanese cedar. In fumigation bioassays, the efficacy order was: tea tree > clove > eucalyptus > lavender > palmarosa > geranium > Japanese cedar > bitter orange > manuka. In both bioassays, cade oil showed no activity.

Conclusion: Essential oils, especially tea tree, clove, palmarosa, and eucalyptus oils, are potential complementary or alternative products to treat $S$. scabiei infections in humans or animals, as well as to control the mites in the environment.

Keywords: Sarcoptes scabiei, Essential oils, Contact, Fumigation bioassay

\section{Background}

Sarcoptes scabiei, a mite of the family Sarcoptidae, causes a contagious pruritic skin disease in humans and in animals. The human infection is called scabies and is estimated to affect more than 130 million people worldwide at any time [1]. For such, scabies was added to the World Health Organization list of neglected tropical diseases in 2013. The animal infection by S. scabiei is devastating and causes significant morbidity and mortality in wild and domestic mammals. It affects more than 100 species worldwide including companion, livestock, and wild animals and is considered as an emerging problem in many countries $[2,3]$.

\footnotetext{
* Correspondence: jacques.guillot@vet-alfort.fr

${ }^{2}$ Research group Dynamyc, EA 7380 EnvA, UPEC, UPE, Maisons-Alfort \& Créteil, France

Full list of author information is available at the end of the article
}

In humans, the treatment of S. scabiei infection is hindered by the suboptimal efficacy of the few available therapies [4]. In veterinary medicine, the number of available acaricides is much higher but the control of animal ectoparasites (including S. scabiei) infections is progressively undermined by the development of resistance to acaricides [5]. In addition, it has been reported that these chemical acaricides induce mild to severe adverse effects [6-8]. For all these reasons, there is an emerging need to develop alternative approaches in ectoparasite management. One of those approaches employs the bioactive effects of plant-derived products. In a recent review, George et al. [6] described the potential pesticidal and repellent effect of plant-derived products such as essential oils, their use, modes of action, and their potential utilization in the prevention and treatment of human and animal ectoparasitoses. Essential oils, which are extracted from plants through 
steam distillation, are complex natural mixtures containing one to three major components at fairly high concentrations [7]. They have been demonstrated to exhibit fumigant and topical toxicity to a number of insect and mite pests, as well as to fungi and bacteria [7, 8]. In Australia, a topical treatment of $5 \%$ tea tree oil combined with benzyl benzoate is used for the treatment of scabies [9].

The aim of this study was to assess the potential efficacy of 10 chemically-characterized essential oils against S. scabiei var. suis.

\section{Methods}

\section{Essential oils}

The acaricide activity was evaluated for 10 essential oils (Table 1). Each of them was diluted with paraffin oil to obtain three concentration levels of the tested oil at 10, 5 and $1 \%$. The dilution was performed right before setting for contact bioassays. In another series of tests, pure essential oils were used for fumigation bioassays. The contact and fumigation tests were performed at room temperature $\left(20 \pm 3{ }^{\circ} \mathrm{C}\right)$ and at $65 \pm 5 \%$ of relative humidity, and were replicated three times.

The main components of the essential oils were analyzed by gas chromatography/mass spectrometry (GC/MS) with an Agilent 5977A Series GC/MSD System. The ability of the columns to separate compounds depends on their stationary phases. According to this principle and considering the potential composition of the oils, a DB-1 MS column $(30 \mathrm{~m} \times 0.25 \mathrm{~mm} \times 0.25 \mu \mathrm{m})$ was used to analyze lavender, tea tree, geranium, manuka, and bitter orange oils, whereas an HP-INNOWax column $(30 \mathrm{~m} \times 0.25 \mathrm{~mm} \times$ $0.25 \mu \mathrm{m}$ ) was used to analyze clove, eucalyptus, cade, palmarosa, and Japanese cedar oils. Helium was the carrier gas. The chemical structure of each component was identified by comparing its fragmentation patterns seen in mass spectra with standard library data. The relative percentage of the oil components was calculated from the GC peak areas.

Table 1 The ten essential oils evaluated in the present study

\begin{tabular}{lll}
\hline Family & Common name & Scientific name \\
\hline Lamiaceae & Lavender & Lavandula angustifolia \\
Rutaceae & Bitter orange & Citrus aurantium amara \\
Geraniaceae & Geranium & Pelargonium asperum \\
Myrtaceae & Tea tree & Melaleuca alternifolia \\
& Clove & Syzygium aromaticum \\
& Eucalyptus & Eucalyptus radiata \\
& Manuka & Leptospermum scoparium \\
Cupressaceae & Cade & Juniperus oxycedrus \\
& Japanese cedar & Cryptomeria japonica \\
Poaceae & Palmarosa & Cymbopogon martini \\
\hline
\end{tabular}

\section{Sarcoptes mites}

Sarcoptes mites were collected from pigs maintained at CRBM (Centre de Recherche Bio Médicale), MaisonsAlfort, France. Pigs were experimentally infected as described by Mounsey et al. [10].

Inoculation was performed by directly inserting miteinfected skin crusts deep into the ear canals of five-week old female piglets. The cutaneous lesions developed first in the ear then spread to the entire body of the pigs. In the present study, mites were collected 9 and 10 weeks post-experimental infection. Skin crusts of the external ear canal were gently removed and placed in a Petri dish. Mites were picked up with a needle one $\mathrm{h}$ after crust collection; giving time to the mites to climb out of the crusts (Additional file 1: Figure S1). Alive mites of all stages (adults, nymphs and larvae) were then placed one by one in a new plastic Petri dish [11].

\section{Contact bioassays}

For each experiment, alive mites of all motile stages $(n=20)$ were placed in a plastic Petri dish ( $3 \mathrm{~cm}$ in diameter). In the first experiment, all the pure essential oils included in the present study were successively tested against mites. The following bioassays were conducted using the essential oils that killed all the mites within $1 \mathrm{~h}$ of direct contact. The selected essential oils were diluted with paraffin to get concentrations at 10, 5 and even $1 \%$ (for the most efficient ones). In each Petri dish, $1 \mathrm{ml}$ of the diluted solution was added in direct contact with the mites. A control Petri dish was inoculated with $1 \mathrm{ml}$ of paraffin oil. The mites were inspected under a stereomicroscope (Nikon@), SMZ645, Lisses, France) 10, 20, 30, 40, 50, 60, 90, 120, 150 and 180 min after inoculation. Mites were considered dead when no movement was seen even after touching it with a needle, and no gut movement was observed over 2 min [12].

\section{Fumigation bioassays}

In a separate experiment, the vapor phase toxicity of the 10 oils was investigated. For each fumigation bioassay, 10 mites of all motile stages were placed at the bottom of a plastic Petri dish (3 cm in diameter). A covering filter paper was put on the lid of the Petri dish and treated with $100 \mu \mathrm{l}$ of the pure essential oil. A control Petri dish was treated with paraffin oil. All the Petri dishes (tested oils and control) were closed and turned over. The mites stayed firmly attached to the bottom of the Petri dish (Additional file 2: Figure S2). They were constantly inspected under a stereomicroscope for the first $5 \mathrm{~min}$, and then every $5 \mathrm{~min}$ for $1 \mathrm{~h}$. Mites death was expressed by the absence of movement in the legs and the gut.

\section{Statistical analyses}

The data were analyzed by Kaplan Meier survival curves and the median lethal times $\left(\mathrm{LT}_{50}\right)$ of scabies mites were 
calculated using JMP 12.0 software. The statistical differences between data obtained with each essential oil and the control for each experiment (contact test with 10, 5 and $1 \%$ oil concentrations, and fumigation test) were measured by Log-rank test expressed by $\chi^{2}$ results and $P$-values (degree of freedom $(\mathrm{df})=1) . P$-value of $\leq 0.05$ was considered significant.

\section{Results}

The major components of the oils analyzed by GC/MS are presented in Table 2. The survival curves of mites exposed to essential oils by direct contact or by fumigation are shown in Fig. 1. The median lethal times are presented in Table 3. In all tests, significant statistical differences were found between each essential oil and the control $(P<0.0001)$ except for the contact test of Japanese cedar oil at $5 \%$ concentration $\left(\chi^{2}=3.0741, P=\right.$ 0.0795) (Table 3). Cade oil failed to show any significant effect in both bioassays. Among all the oils tested with the contact bioassay, clove oil demonstrated the best scabicidal effect as its $1 \%$ solution killed all mites within $20 \mathrm{~min}$. Based on their median lethal times in contact bioassays (Table 3), the efficacy of these oils can be put in this order: clove $>$ palmarosa $>$ geranium $>$ tea tree $>$ lavender $>$ manuka $>$ bitter orange $>$ eucalyptus $>$ Japanese cedar. No mite died when exposed to pure cade oil for one hour.

Concerning the fumigation bioassay, the tea tree oil demonstrated the best efficacy since it killed all the mites in only $4 \mathrm{~min}$, whereas in the contact bioassays, the 10 and 5\% diluted solutions of tea tree took 30 and $90 \mathrm{~min}$ to kill all the mites, respectively. Based on the median lethal times in fumigation bioassays (Table 3), the efficacy of the oils followed this order: tea tree $>$ clove $>$ eucalyptus $>$ lavender $>$ palmarosa $>$ geranium $>$ Japanese cedar $>$ bitter orange $>$ manuka. Cade oil showed no activity against the mites during fumigation bioassays.

Table 2 The major components of the ten essential oils tested in the present study

\begin{tabular}{|c|c|c|c|c|c|c|c|c|c|c|}
\hline Major components & Ivd & bo & grn & $\operatorname{tr}$ & $\mathrm{Cl}$ & ecl & mnk & $\mathrm{cd}$ & jc & plm \\
\hline acetyleugenol & & & & & 16.3 & & & & & \\
\hline cadina-1,4-diene & & & & & & & 5.8 & & & \\
\hline b-cadinene & & & & & & & & 28.6 & & \\
\hline d-cadinene & & & & & & & 6.3 & & & \\
\hline calamenene & & & & & & & 14.0 & & & \\
\hline I-calamenene & & & & & & & & 14.4 & & \\
\hline caryophyllene & & & & & & & & 7.5 & & \\
\hline citronellol & & & 33.4 & & & & & & & \\
\hline 1,8-cineole & & & & & & 78.8 & & & & \\
\hline citronellyl formate & & & 10.9 & & & & & & & \\
\hline o-cymene & & & & & & & & & 5.6 & \\
\hline elemol & & & & & & & & & 17.2 & \\
\hline$\beta$-eudesmol & & & & & & & & & 5.1 & \\
\hline eugenol & & & & & 74.6 & & & & & \\
\hline geraniol & & & 12.0 & & & & & & & 81.4 \\
\hline humulene & & & & & & & & 5.5 & & \\
\hline kaur-16-ene & & & & & & & & & 18.6 & \\
\hline leptospermone & & & & & & & 16.3 & & & \\
\hline linalool & 33.0 & 23.8 & 5.5 & & & & & & & \\
\hline linalyl acetate & 44.1 & 51.8 & & & & & & & & \\
\hline menthone & & & 6.3 & & & & & & & \\
\hline a-pinene & & & & & & & & & 13.9 & \\
\hline sabenene & & & & & & & & & 6.8 & \\
\hline a-terpinene & & & & 9.2 & & & & & & \\
\hline$\gamma$-terpinene & & & & 15.6 & & & & & & \\
\hline terpinen-4-ol & & & & 37.1 & & & & & 5.9 & \\
\hline a-terpineol & & 7.0 & & 5.0 & & 8.7 & & & & \\
\hline
\end{tabular}

Abbreviations: Ivd lavande, bo bitter orange, grn geranium, $t r$ tea tree, $c l$ clove, ecl eucalyptus, mnk manuka; $c d$ cade, jc japanese cedar, plm palmarosa 

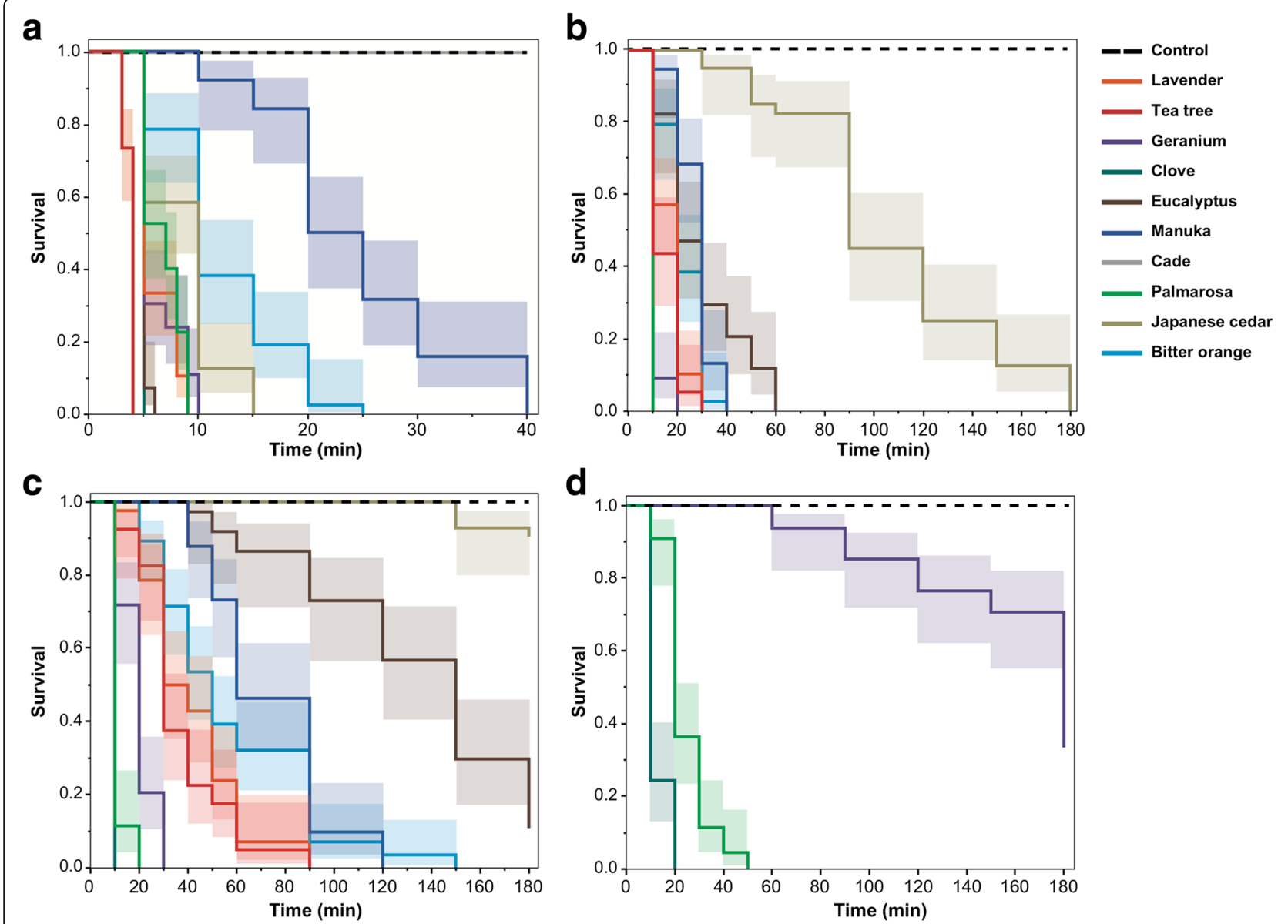

Fig. 1 Survival curves of Sarcoptes scabiei mites exposed to essential oils. a Fumigation test with 10 essential oils. b Contact test with $10 \%$ of 9 essential oils. c Contact test with 5\% of 9 essential oils. $\mathbf{d}$ Contact test with 1\% of 3 essential oils. $95 \%$ confidence intervals are represented as shaded areas

Table 3 Median lethal times ( $\left(\mathrm{LT}_{50}\right)$ of the ten essential oils tested during contact or fumigant bioassays

\begin{tabular}{|c|c|c|c|c|c|c|c|c|c|c|c|c|}
\hline \multirow[t]{2}{*}{ Essential oil } & \multicolumn{3}{|c|}{ Contact with a $10 \%$ solution } & \multicolumn{3}{|c|}{ Contact with a $5 \%$ solution } & \multicolumn{3}{|c|}{ Contact with a $1 \%$ solution } & \multicolumn{3}{|c|}{ Fumigation } \\
\hline & $\mathrm{LT}_{50} \pm \mathrm{SD}$ & $x^{2}$ & $P$ & $\mathrm{LT}_{50} \pm \mathrm{SD}$ & $x^{2}$ & $P$ & $\mathrm{LT}_{50} \pm \mathrm{SD}$ & $x^{2}$ & $P$ & $\mathrm{LT}_{50} \pm \mathrm{SD}$ & $x^{2}$ & $P$ \\
\hline Lavender & $20.0 \pm 6.6$ & 94.7 & $<0.0001$ & $35.0 \pm 20.0$ & 95.0 & $<0.0001$ & - & - & - & $5.0 \pm 1.6$ & 100.7 & $<0.0001$ \\
\hline Tea tree & $10.0 \pm 6.0$ & 89.0 & $<0.0001$ & $30.0 \pm 18.0$ & 95.3 & $<0.0001$ & - & - & - & $4.0 \pm 0.4$ & 81.5 & $<0.0001$ \\
\hline Geranium & $10.0 \pm 2.9$ & 94.2 & $<0.0001$ & $20.0 \pm 7.0$ & 87.7 & $<0.0001$ & $150.0 \pm 40.0$ & 37.1 & $<0.0001$ & $5.0 \pm 1.9$ & 102.1 & $<0.0001$ \\
\hline Clove & 10.0 & 64.0 & $<0.0001$ & 10.0 & 79.0 & $<0.0001$ & $10.0 \pm 4.3$ & 87.9 & $<0.0001$ & 5.0 & 91.0 & $<0.0001$ \\
\hline Eucalyptus & $20.0 \pm 16.0$ & 92.2 & $<0.0001$ & $150.0 \pm 44.0$ & 69.2 & $<0.0001$ & - & - & - & $5.0 \pm 0.3$ & 91.0 & $<0.0001$ \\
\hline Manuka & $30.0 \pm 7.5$ & 86.4 & $<0.0001$ & $60.0 \pm 24.0$ & 89.5 & $<0.0001$ & - & - & - & $23.0 \pm 8.7$ & 91.7 & $<0.0001$ \\
\hline Cade & - & - & - & - & - & & - & - & - & $>60.0$ & & $<0.0001$ \\
\hline Palmarosa & 10.0 & 82.0 & $<0.0001$ & $10.0 \pm 3.2$ & 85.4 & $<0.0001$ & $20.0 \pm 9.3$ & 96.7 & $<0.0001$ & $7.0 \pm 1.7$ & 92.2 & $<0.0001$ \\
\hline Japanese cedar & $90.0 \pm 42.0$ & 93.6 & $<0.0001$ & $180.0 \pm 7.8$ & 3.1 & 0.0795 & - & - & - & $10.0 \pm 3.4$ & 94.4 & $<0.0001$ \\
\hline Bitter orange & $20.0 \pm 8.0$ & 86.5 & $<0.0001$ & $50.0 \pm 33.0$ & 99.6 & $<0.0001$ & - & - & - & $10.0 \pm 5.4$ & 94.0 & $<0.0001$ \\
\hline
\end{tabular}




\section{Discussion}

Many publications already reported the efficacy of essential oils against a wide range of ectoparasites [13]. In a study on poultry red mites, 56 essential oils were tested by either filter-paper contact bioassay or fumigation bioassay. In the first series, cade and horseradish oils resulted in $100 \%$ mite mortality at a concentration of $0.04 \mathrm{mg} \cdot \mathrm{cm}^{-2}$ after $24 \mathrm{~h}$, whereas with the fumigation bioassays the same result was obtained with cade, clove bud, coriander, horseradish, and mustard oils at $0.28 \mathrm{mg} . \mathrm{cm}^{-2}$ after $24 \mathrm{~h}$ [14]. In other studies, on Psoroptes mites, the Laurus novocanariensis oil at $5 \%$ concentration killed all the mites after $24 \mathrm{~h}$ of contact [15], and $0.5 \mathrm{~g} / \mathrm{ml}$ and $1 \mathrm{~g} / \mathrm{ml}$ extracts of Eupatorium adenophorum resulted in a $\mathrm{LT}_{50}$ of $0.93 \mathrm{~h}$ and $1.29 \mathrm{~h}$, respectively [16].

To our knowledge, the research work covering the efficacy of essential oils against S. scabiei is limited in number as only eight botanical extracts including essential oils and their components have been tested in vitro. Among them, neem (Azadirachta indica) and tea tree (Melaleuca alternifolia) oils were specifically examined for the purpose [17-23]. Other natural products of concern include clove (Syzygium aromaticum), nugmeg (Myristica fragrans), and ylangylang (Cananga odorata) oils, as well as plant extracts from Eupatorium adenophorum, Ailanthus altissima and Ligularia virgaurea $[12,16,24-26]$. Although the efficacies of tea tree and clove oils against Sarcoptes mites have already been reported, the current study allowed us, for the first time, to compare these two oils together and with other oils. Pasay et al. reported that $1.56 \%$ clove oil killed all S. scabiei mites after $15 \mathrm{~min}$ in contact bioassay [12], which is consistent with the result of the present study (1\% clove oil killed all the mites in $20 \mathrm{~min}$ ). In another study, clove oil also showed toxicity against house dust mite Dermatophagoides pteronyssinus [27]. The lethal time of 5\% tea tree oil was reported $180 \mathrm{~min}$ [18], whereas in our investigation, all mites died after 90 and $30 \mathrm{~min}$ of exposure to 5 and $10 \%$ tea tree oil, respectively. Furthermore, our findings showed no scabicidal effect with cade oil which was previously demonstrated effective against head lice and poultry red mites $[14,28]$. This inconsistency can be attributed to the varied chemical components of the studied essential oils which are influenced by the method of extraction, type of solvent, date of harvesting, as well as the geographical origin and the selected parts of a single plant species [29].

The fumigant effect of essential oils was studied on stored products pests, head lice, ticks, and Psoroptes mites [28, 30-32], but never on S. scabiei. A notable finding to report here is the strong fumigant efficacy the tested oils have on scabies mites. However, the fumigant efficacy order of the oils did not exactly match their contact efficacy order. Similar discrepancies were reported in studies on contact and fumigant effects of essential oils against agricultural pests [33, 34]. For instance, in contact bioassays, the median lethal times for $1 \%$ clove and palmarosa were $10 \pm 4.3 \mathrm{~min}$ and $20 \pm 9.3 \mathrm{~min}$, respectively (Table 3 ). In fumigation bioassays, tea tree oil $\left(\mathrm{LT}_{50}=4 \pm 0.4\right)$ was the most effective, followed by clove $\left(\mathrm{LT}_{50}=5\right)$ and eucalyptus oils $\left(\mathrm{LT}_{50}=5 \pm 0.3\right)$ (Table 3). These results suggest that eugenol, a major component of clove oil (Table 2), exhibits strong contact and fumigant effects against S. scabiei mites. Geraniol, which is the main component of palmarosa oil, seems to have strong contact effect but much less fumigant effect. On the contrary, terpinen-4-ol, the main component of tea tree oil, and 1,8-cineole, the main component of eucalyptus oil, were much more active by fumigation than by contact. The volatiles of essential oils are mostly terpenoid substances, particularly monoterpenes (C10) [35], and depending on the type of the bioassay method used in the study, the insecticidal or acaricidal effects of monoterpenes could vary. For example, 1,8-cineole, which is a major component of eucalyptus, rosemary, and tea tree oils, showed a toxic effect in fumigation bioassays against the Sitophilus oryzae and Tribolium castaneum insects, but was much less effective in contact bioassays. Exactly opposite geraniol which had strong contact toxicity but low fumigant activity [34]. Some monoterpenes could play an important role in ectoparasite management thanks to their fumigant efficacy. Linalool, terpinen-4-ol, geraniol, and eugenol possess potent activity against Psoroptes cuniculi, whereas linalyl acetate and estragole were almost ineffective against this parasite [31]. Since linalool and linalyl acetate are two main components in both lavender and bitter orange oils (Table 2), their variable efficacy against S. scabiei, as demonstrated in the present study, could be attributed to the variation in their percentages in these oils. On the other hand, the discrepancies between contact and fumigation bioassays can also be explained by the mode of absorption of the active ingredient by the mites. In contact bioassays, the toxic compounds directly penetrate the cuticle layer of the arthropod. In fumigation bioassays, the toxic compounds are inhaled via the respiratory system. Therefore, compounds which are lipophilic and viscous might have better performance in contact bioassays, whereas in fumigation bioassays, the vapor pressure may determine the compound efficacy [36].

In this study, the observation time was relatively short (180 min for contact bioassays and $60 \mathrm{~min}$ for fumigation bioassays). This is the reason why we believe that using a mixture of instars had a limited effect on our results, although females and nymphs were found surviving longer than males and larvae in the environment [11]. Twenty mites were used for each contact bioassay and only 10 mites for each fumigation bioassay. These 
numbers can be considered low but the mites were observed every 5 or $10 \mathrm{~min}$ (for contact or fumigation bioassays, respectively), so including a larger number of mites might have increased the risk of miscount.

New research work has been directed to study the essential oils mechanism of action on Sarcoptes mites. For instance, $\mathrm{Hu}$ et al. [37] have recently found that 1,8-cineole increases the activities of superoxide dismutase and glutathione-s-transferase enzymes, which are involved in the protection mechanism of $S$. scabiei mites. The same compound was also shown to affect the nervous system of the mite by increasing the activity of monoamine oxidase and inhibiting acetylcholinesterase.

Essential oils have extensively been used as fragrances, aromatherapy and in pharmaceutical industry for centuries [29]. Given the historically widespread use of them, we might expect these compounds to be relatively safe. Previous studies showed that the great majority of essential oils is 'slightly toxic' or 'non-toxic' to mammals [38]. However, adverse skin reactions to essential oils have been documented. A review on patch tests using tea tree oil demonstrated that $1.8 \%$ of the participants had positive allergic reactions [39]. For such, preventive measures include lowering the concentration and eliminating the main allergens from the original oils [38].

\section{Conclusion}

The present study demonstrated that several essential oils (except cade oil) have both contact and fumigant effects against S. scabiei var. suis. Essential oils, especially tea tree, clove (for both fumigant and contact use), eucalyptus (for fumigant use), and palmarosa (for contact use), should be considered as complementary or alternative therapies to chemical acaricides in the treatment of $S$. scabiei infections, as well as in the environmental control of the mites.

\section{Additional files}

Additional file 1: Figure S1. Thousands of mites on the crusts collected from the ear canal of the pig model. (JPG 639 kb)

Additional file 2: Figure S2. The mites in fumigation bioassay observed under a stereomicroscope. The mites stayed firmly attached to the bottom of the Petri dish which has been turned over. (JPG $400 \mathrm{~kb}$ )

\section{Abbreviations}

CRBM: Centre de Recherche BioMédicale; LT: Lethal time

\section{Acknowledgements}

Fang Fang's PhD grant was provided by China Scholarship Council. For such we would like to express our deep thanks to the council.

\section{Availability of data and materials}

The datasets supporting the conclusions of this article are included within the article and its additional files.

\section{Authors' contributions \\ $J G, W H, O C, F B$, and $\mathrm{Al}$ conceived the study and revised the manuscript. FF, $\mathrm{CB}$ and KC carried out the tests and collected data. FF and LC carried out GC/MS analysis. Al provided the essential oils. EM was responsible for the statistical analysis and FF drafted the manuscript. All authors read and approved the final manuscript.}

\section{Competing interests}

The authors declare that they have no competing interests.

\section{Consent for publication}

Not applicable.

\section{Ethics approval and consent to participate}

Mites were collected from experimentally infected pigs which were maintained in strict respect to the guidelines as defined by the French and European code of good practice for the care and use of animals for scientific purposes (French Ministry of Research approval no: 02515.03).

\section{Author details}

${ }^{1}$ Parasitology Department, College of Animal Science and Technology, Guangxi University, Nanning, China. ${ }^{2}$ Research group Dynamyc, EA 7380 EnvA, UPEC, UPE, Maisons-Alfort \& Créteil, France. ${ }^{3}$ Parasitology-Mycology Department, AP-HP, Hôpital Avicenne, Bobigny, France. ${ }^{4}$ Dermatology Department, AP-HP, Henri Mondor Hospital, UPEC, Créteil, France. ${ }^{5}$ Guangxi Key Laboratory of Traditional Chinese Medicine Quality Standards, Guangxi Institute of Traditional Medical and Pharmaceutical Sciences, Nanning, China.

Received: 8 August 2016 Accepted: 15 November 2016

Published online: 22 November 2016

References

1. Currie BJ. Scabies and global control of neglected tropical diseases. N Engl J Med. 2015;373:2371-2.

2. Currier RW, Walton SF, Currie BJ. Scabies in animals and humans: history, evolutionary perspectives, and modern clinical management: Currier et al. Ann N Y Acad Sci. 2011;1230:E50-60.

3. Alasaad S, Rossi L, Heukelbach J, Pérez JM, Hamarsheh O, Otiende M, et al. The neglected navigating web of the incomprehensibly emerging and re-emerging Sarcoptes mite. Infect Genet Evol. 2013;17:253-9.

4. Strong M, Johnstone P. Interventions for treating scabies. Cochrane Database Syst Rev. 2007;18:CD000320

5. Mounsey KE, Holt DC, McCarthy J, Currie BJ, Walton SF. Scabies: molecular perspectives and therapeutic implications in the face of emerging drug resistance. Future Microbiol. 2008:3:57-66.

6. George DR, Finn RD, Graham KM, Sparagano OA. Present and future potential of plant-derived products to control arthropods of veterinary and medical significance. Parasit Vectors. 2014;7:28.

7. Bakkali F, Averbeck S, Averbeck D, Idaomar M. Biological effects of essential oils - a review. Food Chem Toxicol. 2008:46:446-75.

8. Regnault-Roger $\mathbf{C}$. The potential of botanical essential oils for insect pest control. Integr Pest Manag Rev. 1997;2:25-34.

9. Thomas J, Carson CF, Peterson GM, Walton SF, Hammer KA, Naunton M, et al. Therapeutic Potential of Tea Tree Oil for Scabies. Am J Trop Med Hyg. 2016;94:258-66

10. Mounsey K, Ho M-F, Kelly A, Willis C, Pasay C, Kemp DJ, et al. A tractable experimental model for study of human and animal scabies. PLoS Negl Trop Dis. 2010;4:e756.

11. Fang F, Bernigaud C, Candy K, Melloul E, Izri A, Durand R, et al. Efficacy assessment of biocides or repellents for the control of Sarcoptes scabiei in the environment. Parasit Vectors. 2015;8:416.

12. Pasay C, Mounsey K, Stevenson G, Davis R, Arlian L, Morgan M, et al. Acaricidal activity of eugenol based compounds against scabies mites. PLoS One. 2010;5:e12079. Munayco CV, editor.

13. Ellse L, Wall R. The use of essential oils in veterinary ectoparasite control: a review. Med Vet Entomol. 2014;28:233-43.
Funding

Not applicable. 
14. Kim S-I, Yi J-H, Tak J, Ahn Y-J. Acaricidal activity of plant essential oils against Dermanyssus gallinae (Acari: Dermanyssidae). Vet Parasitol. 2004;120:297-304.

15. Macchioni F, Perrucci S, Cioni P, Morelli I, Castilho P, Cecchi F. Composition and acaricidal activity of Laurus novocanariensis and Laurus nobilis essential oils against Psoroptes cuniculi. J Essent Oil Res. 2006;18:111-4.

16. Nong X, Fang C-L, Wang J-H, Gu X-B, Yang D-Y, Liu T-F, et al. Acaricidal activity of extract from Eupatorium adenophorum against the Psoroptes cuniculi and Sarcoptes scabiei in vitro. Vet Parasitol. 2012;187:345-9.

17. Walton SF, Myerscough MR, Currie BJ. Studies in vitro on the relative efficacy of current acaricides for Sarcoptes scabiei var. hominis. Trans R Soc Trop Med Hyg. 2000;94:92-6.

18. Walton SF, McKinnon M, Pizzutto S, Dougall A, Williams E, Currie BJ. Acaricidal activity of Melaleuca alternifolia (tea tree) oil: in vitro sensitivity of Sarcoptes scabiei var hominis to terpinen-4-ol. Arch Dermatol. 2004;140:563-6.

19. Du Y-H, Jia R-Y, Yin Z-Q, Pu Z-H, Chen J, Yang F, et al. Acaricidal activity of extracts of neem (Azadirachta indica) oil against the larvae of the rabbit mite Sarcoptes scabiei var. cuniculi in vitro. Vet Parasitol. 2008;157:144-8.

20. Du Y-H, Li J-L, Jia R-Y, Yin Z-Q, Li X-T, Lv C, et al. Acaricidal activity of four fractions and octadecanoic acid-tetrahydrofuran-3,4-diyl ester isolated from chloroform extracts of neem (Azadirachta indica) oil against Sarcoptes scabiei var. cuniculi larvae in vitro. Vet Parasitol. 2009;163:175-8.

21. Xu J, Fan Q-J, Yin Z-Q, Li X-T, Du Y-H, Jia R-Y, et al. The preparation of neem oil microemulsion (Azadirachta indica) and the comparison of acaricidal time between neem oil microemulsion and other formulations in vitro. Vet Parasitol. 2010;169:399-403.

22. Deng Y, Shi D, Yin Z, Guo J, Jia R, Xu J, et al. Acaricidal activity of petroleum ether extract of neem (Azadirachta indica) oil and its four fractions separated by column chromatography against Sarcoptes scabiei var. cuniculi larvae in vitro. Exp Parasitol. 2012;130:475-7.

23. Seddiek SA, Khater HF, El-Shorbagy MM, Ali AM. The acaricidal efficacy of aqueous neem extract and ivermectin against Sarcoptes scabiei var. cuniculi in experimentally infested rabbits. Parasitol Res. 2013:112:2319-30.

24. Gu X, Fang C, Yang G, Xie Y, Nong X, Zhu J, et al. Acaricidal properties of an Ailanthus altissima bark extract against Psoroptes cuniculi and Sarcoptes scabiei var. cuniculi in vitro. Exp Appl Acarol. 2014;62:225-32.

25. Chen Z, Deng Y, Yin Z, Wei Q, Li M, Jia R, et al. Studies on the acaricida mechanism of the active components from neem (Azadirachta indica) oil against Sarcoptes scabiei var. cuniculi. Vet Parasitol. 2014;204:323-9.

26. Luo B, Liao F, Hu Y, Liu XI, He Y, Wu L, et al. Acaricidal activity of extracts from Ligularia virgaurea against the Sarcoptes scabiei mite in vitro. Exp Ther Med. 2015;10:247-50.

27. Saad E-Z, Hussien R, Saher F, Ahmed Z. Acaricidal activities of some essential oils and their monoterpenoidal constituents against house dust mite, Dermatophagoides pteronyssinus (Acari: Pyroglyphidae). J Zhejiang Univ Sci B. 2006;7:957-62

28. Yang Y-C, Lee H-S, Clark JM, Ahn Y-J. Insecticidal activity of plant essential oils against Pediculus humanus capitis (Anoplura: Pediculidae). J Med Entomol. 2004:41:699-704

29. Burt S. Essential oils: their antibacterial properties and potential applications in foods-a review. Int J Food Microbiol. 2004;94:223-53.

30. Cetin H, Cilek JE, Aydin L, Yanikoglu A. Acaricidal effects of the essential oil of Origanum minutiflorum (Lamiaceae) against Rhipicephalus turanicus (Acari: Ixodidae). Vet Parasitol. 2009;160:359-61.

31. Perrucci S, Macchioni G, Cioni PL, Flamini G, Morelli I. Structure/activity relationship of some natural monoterpenes as acaricides against Psoroptes cuniculi. J Nat Prod. 1995;58:1261-4.

32. Lee B-H, Annis PC, Tumaalii F, Choi W-S. Fumigant toxicity of essential oils from the Myrtaceae family and 1,8-cineole against 3 major stored-grain insects. J Stored Prod Res. 2004:40:553-64.

33. Mahfuz I, Khalequzzaman M. Contact and fumigant toxicity of essential oils against Callosobruchus maculatus. Univ J Zool Rajshahi Univ. 2007;26:63-6.

34. Abdelgaleil SAM, Mohamed MIE, Badawy MEI, El-arami SAA. Fumigant and contact toxicities of monoterpenes to Sitophilus oryzae (L.) and Tribolium castaneum (Herbst) and their Inhibitory effects on acetylcholinesterase Activity. J Chem Ecol. 2009;35:518-25.

35. Figueiredo AC, Barroso JG, Pedro LG, Scheffer JJC. Factors affecting secondary metabolite production in plants: volatile components and essential oils. Flavour Fragr J. 2008:23:213-26.
36. Gonzalez-Audino P, Picollo MI, Gallardo A, Toloza A, Vassena C, MougabureCueto $\mathrm{G}$. Comparative toxicity of oxygenated monoterpenoids in experimental hydroalcoholic lotions to permethrin-resistant adult head lice. Arch Dermatol Res. 2011;303:361-6.

37. Hu Z, Chen Z, Yin Z, Jia R, Song X, Li L, et al. In vitro acaricidal activity of 1,8-cineole against Sarcoptes scabiei var. cuniculi and regulating effects on enzyme activity. Parasitol Res. 2015;114:2959-67.

38. Tisserand R, Young R. Essential oil safety: a guide for health care professionals: second edition. UK: Elsevier Health Sciences; 2013.

39. Rutherford T, Nixon R, Tam M, Tate B. Allergy to tea tree oil: retrospective review of 41 cases with positive patch tests over 4.5 years. Australas. J Dermatol. 2007;48:83-7.

\section{Submit your next manuscript to BioMed Central and we will help you at every step:}

- We accept pre-submission inquiries

- Our selector tool helps you to find the most relevant journal

- We provide round the clock customer support

- Convenient online submission

- Thorough peer review

- Inclusion in PubMed and all major indexing services

- Maximum visibility for your research

Submit your manuscript at www.biomedcentral.com/submit
) Biomed Central 